PREPARED FOR THE U.S. DEPARTMENT OF ENERGY, UNDER CONTRACT DE-AC02-76-CHO-3073

PPPL-2865

UC-420,427

KINETIC STUDIES OF MICROINSTABILITIES IN TOROIDAL PLASMAS: SIMULATION AND THEORY

BY

W.W. LEE, T.S. HAHM, S.E. PARKER, F.W. PERKINS, ET AL.

DECEMBER, 1992
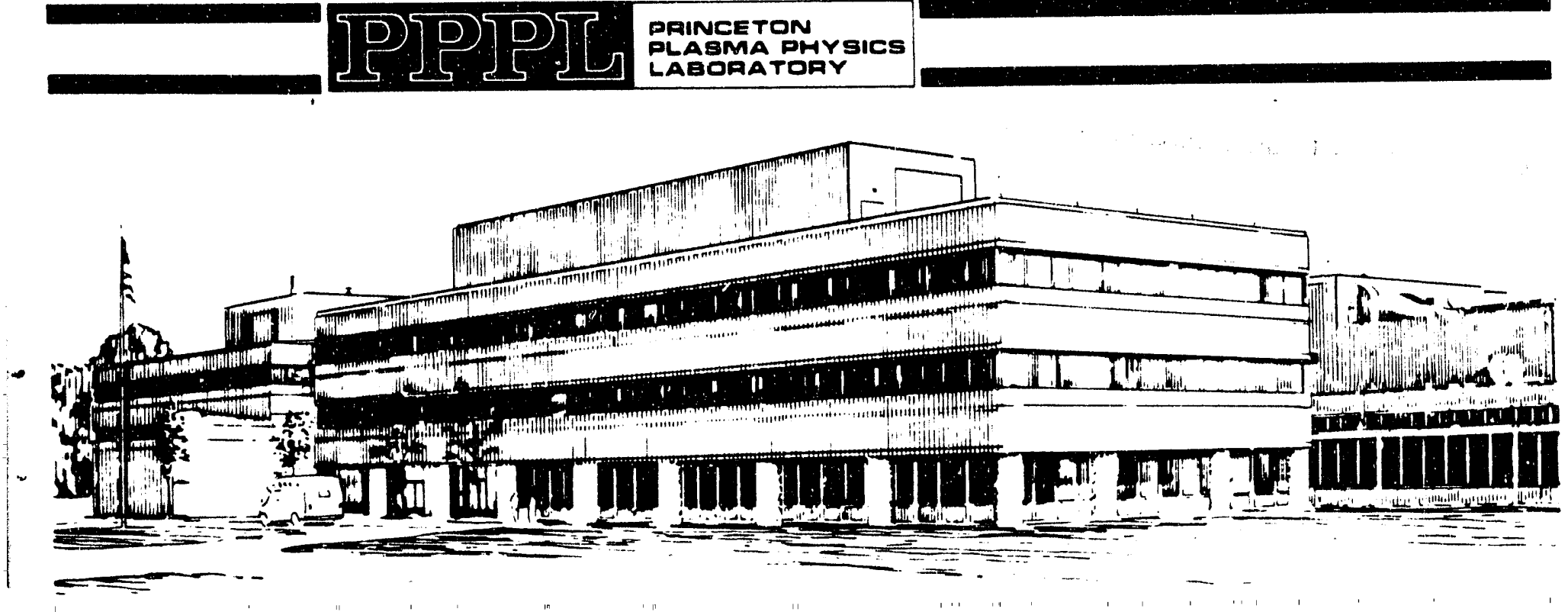


\section{NOTICE}

This report was prepared as an account of work sponsored by an agency of the United States Government. Neither the United States Government nor any agency thereof, nor any of their employees, makes any warranty, express or implied, or assumes any legal liability or responsibility for the accuracy, completeness, or usefulness of any information, apparatus, product, or process disclosed, or represents that its use would not infringe privately owned rights. Reference herein to any specific commercial produce, process, or service by trade name, trademark, manufacturer, or otherwise, does not necessarily constitute or imply its endorsement, recommendation, or favoring by the United States Government or any agency thereof. The views and opinions of authors expressed herein do not necessarily state or reflect those of the United States Government or any agency thereof.

\section{NOTICE}

This report has been reproduced from the best available copy. Available in paper copy $a_{1}$ id microfiche.

Number of pages in this report: 9

DOE and DOE contractors can obtain copies of this report from:

Office of Scientific and Technical Information

P.O. Box 62

Oak Ridge, TN 37831 ;

(615) $576-8401$.

This report is publicly available from the:

National Technical Information Service

Department of Commerce

5285 Port Royal Road

Springfield, Virginia 22161

(703) $487-4650$ 
PPPL--2865

DE93 005725

\title{
KINETIC STUDIES OF MICROINSTABILITIES IN TOROIDAL PLASMAS: SIMULATION AND THEORY*
}

\author{
W.W. LEE, T.S. HAHM, S.E. PARKER, F.W. PERKINS, S. RATH, \\ G. REWOLDT, J.V.W. REYNDERS, R. A. SANTORO and W.M. TANG \\ Princeton Plasma Physics Laboratory, Princeton University, \\ P. O. Box 451 \\ Princeton, New Jersey, USA 08543 \\ - Presented at the Fourteenth International Conference on Plasma Physics and \\ Controlled Nuclear Fusion Research, \\ Wurzburg, Germany, Septemer 30 - October 7, 1992
}

\begin{abstract}
A comprehensive program for the development and use of particle simulation techniques for solving the gyrokinetic Vlasov-Maxwell equations on massively parallel computers has been carried out at Princeton Plasma Physics Laboratory. This is a key element of our ongoing theoretical efforts to systematically investigate physics issues vital to understanding tokamak plasmas. In this paper, our focus is on spatial-gradient-driven microinstabilities. Their importance is supported by the recent progress in achieving a physics-based understanding of anomalous transport in toroidal systems which has been based on the propusition that these drift-type electrostatic modes dependent on ion temperature gradient (ITG) and trapped particle effects are dominant in the bulk ("confinement") region. Although their presence is consistent with a number of significant confinement trends, results from high temperature tokamaks such as TFTR have highlighted the need for better insight into the nonlinear properties of such instabilities in long-mean-free-path plasmas. In addressing this general issue, we report important new results including (i) the first fully toroidal 3D gyrokinetic simulation of ITG modes and (ii) realistic toroidal eigenmode calculations demonstrating the unique capability to deal with large scale kinetic behavior extending over many rational surfaces. The effects of ITG modes (iii) on the inward pinch of impurities in 3D slab geometry and (iv) on the existence of microtearing modes in 2D slab are also discussed. Finally, (v) sheared toroidal flow effects on trapped-particle modes are presented.
\end{abstract}

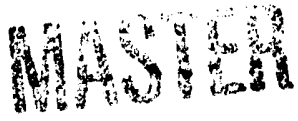


With the advent of simulation techniques [1-3] for the gyrokinetic Vlasov-Maxwell equations and the progress made in simulation algorithms utilizing massively parallel architecture, we have developed an efficient 3D gyrokinetic particle code in toroidal $\left(x=r \cos \theta, y=r \sin \theta, \zeta=-R_{0} \varphi\right.$ ! Teometry implemented on the Connection Machine (CM200) for the systematic kin. .... investigation of ITG instabilities. In order to gain a better understanding of the linear and nonlinear behavior of these modes, we have carried out three types of simulations: linearized [2], partially linearized [2] and fully nonlinear [3]. In the linearized simulation the most unstable modes with ballooning-type mode structures of moderate $(m, n)$ with $k_{r} \ll k_{\theta}$ have been observed to dominate the time evolution of the instability as shown in Fig. 1. This is basically a benchmarking procedure in that it involves comparisons with results from realistic linear toroidal eigenmode calculations [4]. Good agreement is found with respect to both the magnitude of the eigenvalues (within 25\%) and the characteristic features of the eigenfunctions, which exhibit strong ballooning in the poloidal direction and radially extend over many rational surfaces. In the partially linearized simulation, the EXB advection is the only nonlinearity kept and is the mechanism responsible for the nonlinear saturation of the instability. The results in the nonlinear stage of development indicate that (i) the fluctuations become much more isotropic as shown in Fig. 1, but the ballooning structure persists; (ii) the energy cascades to both longer and shorter wavelength modes; (iii) the fluctuation spectrum in the ballooning region peaks at $k_{\theta} \rho_{i} \approx 0.12$ and $k_{r} \rho_{i} \approx 0$; and (iv) the energy flux from the toroidal simulation, which is greatly enhanced over its slab counterpart, scales more like gyro-Bohm and peaks slightly toward the outside of the region of maximum growth. Fully nonlinear simulations are also carried out with results compared to those from the partially linearized simulation. The objective here is to look for insights into the possible origins of ITG transport in steady state. A recent 1D simulation, in which only the velocity-space nonlinearity is kept, has shown the importance of resonance overlap and particle stochasticity in relation to anomalous transport and entropy production in the steady state. This observation is consistent with the previous 2D simulation, where particle stochasticity due to the combined EXB and velocity space nonlinearities has been investigated as the possible cause for transport [5].

In addition to providing valuable self-consistent benchmarks for the aforementioned gyrokinetic simulations, realistic kinetic toroidal eigenmode calculations have been carried out to support a proper assessment of the influence of long-wavelength microturbulence on transport in tokamaks. This is a very relevant 
issue in that scattering diagnostics have generally indicated that the largest fluctuation amplitudes occur at the longest measurable wavelengths. New diagnostics [beam emission spectroscopy (BES) and reflectometry] have recently been implemented on TFTR to address this problem. Motivated by these considerations, we have calculated the fully $2 D(r, \theta)$ mode structures for long-wavelength trapped-ion and toroidal ITG modes using a comprehensive toroidal finite-element code with the unique capability for evaluating large scale kinetic behavior extending over many rational surfaces. Improvements over previously used numerical procedures [1] were necessary in order to tractably evaluate eigenvalues for realistic tokamak parameters. An important new result from the present studies is that, in contrast to the long-accepted picture predicted by $1 \mathrm{D}$ radial eigenmode calculations and supported by earlier idealized (very weak magnetic shear) 2D calculations [4], we find that trapped-ion eigenmodes are not strongly localized between rational surfaces. In fact, even for very long wavelengths the eigenfunctions generally exhibit a strong ballooning character with the associated radial structure relatively insensitive to ion Landau damping at the rational surfaces. This trend is further supported by results obtained from the most comprehensive existent 10 kinetic ballooning code [6] which shows agreement within less than $50 \%$ with the eigenvalues from the $2 D$ code. The linear growth rate spectrum for a representative TFTR plasma is displayed in Fig. 2. Results of this type demonstrate that employed together, our 2-D and 1-D codes provide a unique capability for calculating the linear properties of toroidal microinstabilities over the entire spectral range of interest. It is worthwhile to note that very recent BES measurements in TFTR plasmas have indicated a possible peaking of the spectrum just beyond $k_{\theta} \rho_{i}=0.1-$ a trend qualitatively similar to that displayed in Fig. 2. Results from the present studies of particular relevance to the development of nonlinear models of microturbulence include a significantly revised picture of the radial extent of long-wavelength instabilities such as trapped-ion modes and a demonstration of the capability to provide a realistic picture of the driven versus damped (inertial) regions of the spectrum.

Impurity transport properties in the presence of microturbulence have also been studied using gyrokinetic simulations. In particular, results from 3D sheared slab simulations have provided insight into the physics responsible for the inward pinch of impurities in the presence of ITG modes. It is found that the parallel acceleration in the poloidal direction and the EXB advection in the radial direction give rise to the observed inward pinch of the impurity ions in both the linear and nonlinear stages of 
development. This is true even when both the bulk ions and impurity ions have a flat density profile. However, the pinch is sensitive the temperature gradient of the impurities as well as the $\eta_{i}\left(\equiv L_{n} / L_{T i}\right)$ value for the bulk ions. Because particle diffusion is intrinsically ambipolar, the inward flux for the impurity ions is compensated by the outward flux of the primary ions for an instability in which the electron response is nearly adiabatic. Since the concentration for the impurities is usually very low, their average inward velocity is, therefore, much higher than that of the primary ions. Simulations with heavier impurities have also confirmed this trend as well as the $Z / M$ scaling predicted by our theory. Comparisons with results from ongoing toroidal simulations of this type as well as with those from experimental studies of impurity transport [7] are encouraging.

In order to make further progress in simulating realistic tokamak plasmas, it is necessary to include finite- $\beta$ physics as well as non-adiabatic trapped-electron dynamics in our toroidal code. Electromagnetic codes in $1 \mathrm{D}$ and $2 \mathrm{D}$ slab geometry have been developed to study the influence of magnetic perturbations on the stability and transport of microinstabilities in general and on ITG modes in particular. The results have confirmed the theoretical prediction of finite- $B$ stabilitization due to finite-Larmor-radius effects. Furthermore, we have found that higher radial harmonics of the ITG eigenmodes cannot be fully stabilized by the finite- $\beta$ effects, and, consequently, we have observed the existence of microtearing modes near the rational surfaces in the simulation. The investigation of microtearing effects on anomalous transport and the building of a finite- $B$ toroidal gyrokinetic code are ongoing projects. With respect to non-adiabatic trapped-electron dynamics, a bounce-averaged response is the most efficient representation since the characteristic frequencies of interest are well below the electron bounce frequency. For collisionless trapped-electron modes we have developed a fluid-type model in which energy and pitch-angle distributions are fixed but the dispersion of toroidal precession velocities with energy is retained. This captures the main destabilizing driving mechanism, retains the dominant ExB nonlinearity, and is computable in a three dimensional space.

In light of their large radial extent, it is important to examine the sensitivity of trapped-ion eigenmodes to sheared toroidal flow effects. We begin by noting that valuable insight into the single-particle ion orbit properties can be gained by using the action-variational method in an extended phase space. Sheared flow is shown to induce ellipticity of the Larmor orbit which modifies the first adiabatic invariant $\mu$. The 
gyrokinetic equation is thereby also modified and can be expressed in terms of the effective potentials, $A^{*}=A+(m / q) v \| b$, and $\Phi^{*}=\Phi+(m / 2 q) v_{E}^{2}$. New analytical formulas for the second adiabatic invariant $J$, the bounce frequency, the precession frequency, the banana radial width, the transit frequency, and the fraction of trapped particles are obtained for flow values up to Mach one. These results indicate that in the context of the simplest local theory, toroidal plasma rotation can increase both the fraction of trapped particles and their precession drift velocity and thereby tend to enhance the destabilization of trapped-ion modes [8]. With respect to trapped-electron modes, we find that toroidal shear flow can enhance the nonlinear ion Landau damping of moderately long-wavelength dissipative trapped-electron modes not orily by modifying the beat wave-ion resonance condition but also by changing the radial dependence of the linear susceptibility. At saturation the spectral intensity of the fluctuations is found to scale with flow shear as $\left(\partial V_{\phi} / \partial r\right)^{-2}$ and decays according to a power law $k_{\theta}{ }^{-1}$ [9]. Toroidal rotation can also increase the precession drift frequency influencing the collisionless trapped-electron mode. Here the enhanced trapped-electron Compton scattering results in a stronger forward spectral transfer. Therefore, the longer wavelength part of spectrum is expected to be suppressed. The implications of these new trends are under investigation.

\section{ACKNOWLEDGMENT}

This work is supported by the U. S. Deparment of Energy Contract No.

DE-AC02-76CHO3073.

\section{REFERENCES}

[1] W. W. Lee, J. Comp. Phys. 72, 243 (1987);

[2] A. M. Dimits and W. W. Lee (to appear in J. of Comput. Phys.);

[3] S. E. Parker and W. W. Lee (to appear in Phys. Fluids).

[4] R. Marchand, W. M. Tang and G. Rewoldt, Phys.Fluids 23, 1164 (1980).

[5] A. M. Dimits and W. W. Lee, Phys. Fluids B3, 1557 (1991).

[6] G. Rewoldt and W.M.Tang, Phys.Fluids B2, 318 (1990).

[7] E. J. Synakowski, et al., Phys. Rev. Lett. 65, 2255 (1990).

[8] T. S. Hahm, PPPL-2843 (1992)

[9] T. S. Hahm, Phys. Fluids B4, 2801 (1992).

\section{FIGURE CAPTIONS}

Figure 1. Poloidal cross section of the electrostatic potential during the linear phase $\Omega_{\mathrm{i}} \mathrm{t}=500$ (left) and the saturated turbulent state $\Omega_{\mathrm{i}} \mathrm{t}=12,500$ (right) of the ITG instability for the $128 \times 128 \times 64$ grid with $1,048,576$ particles ( $L T=50 \mathrm{p}$, $\left.\Delta x=\Delta y=1.5 p_{i}, a=96 \rho_{i}\right)$.

Figure 2. Representative linear spectrum (growth rate vs. toroidal mode number) for realistic TFTR L-mode discharge parameters. 

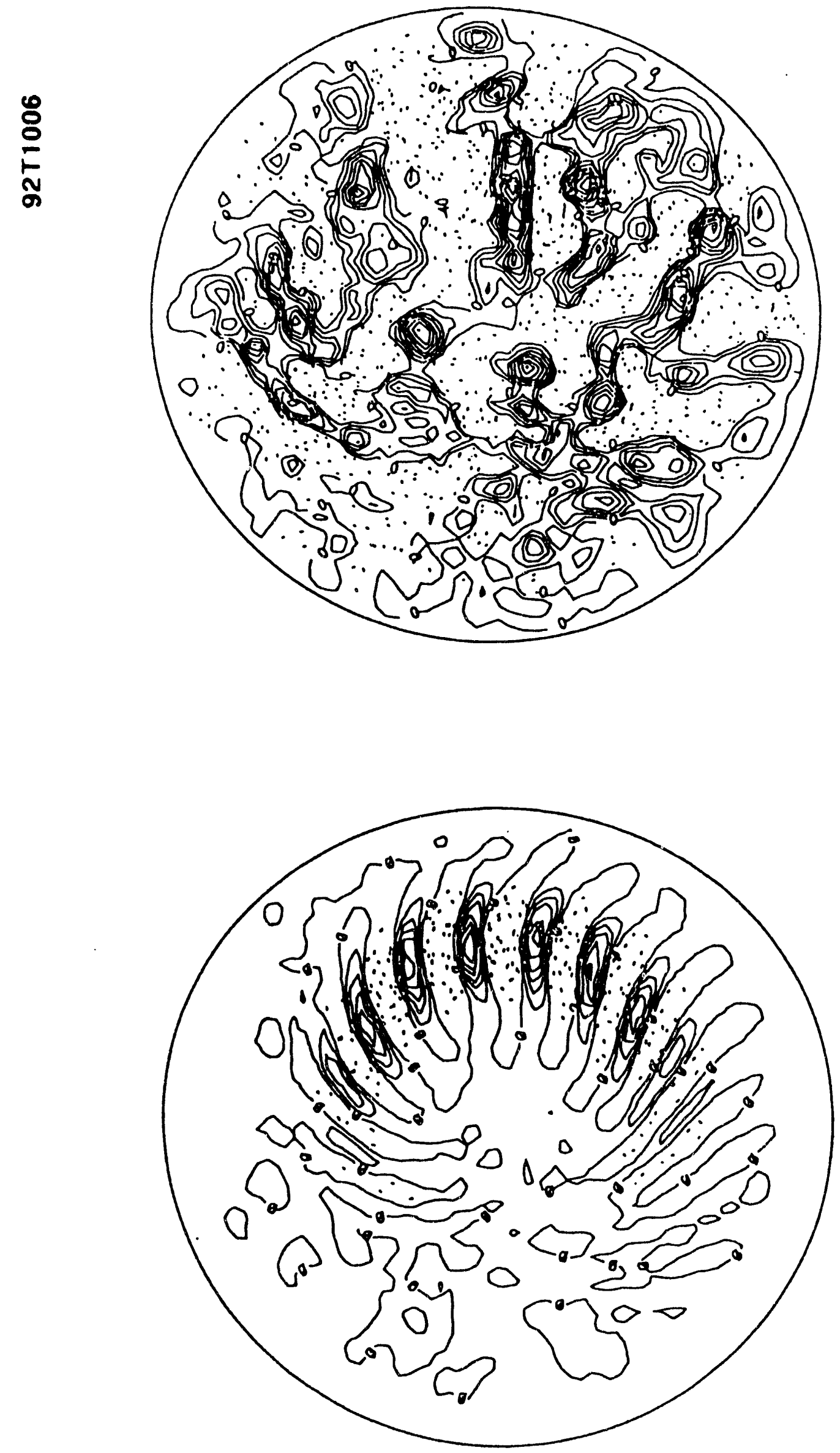
옹
ำ

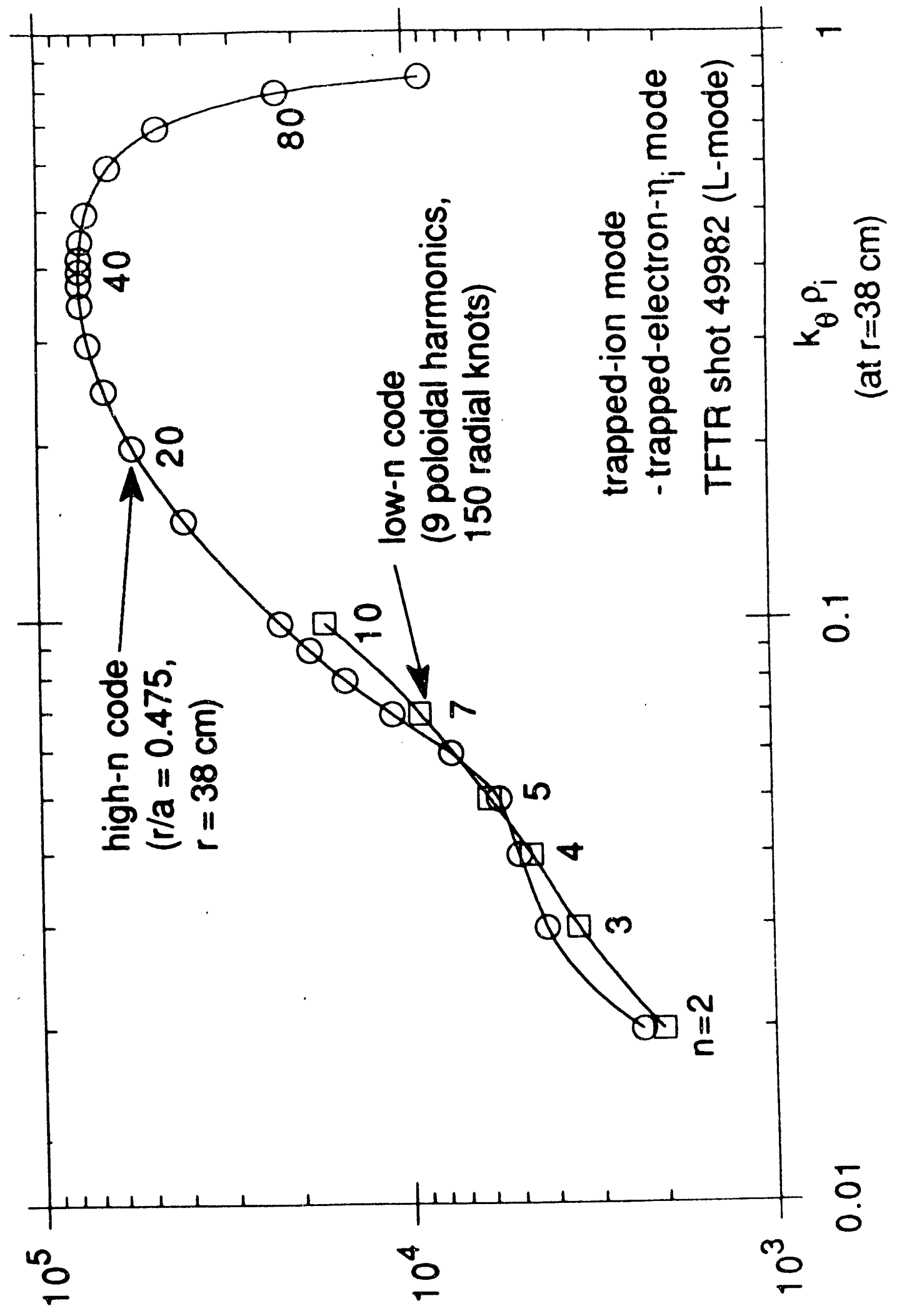

$N$
$\stackrel{0}{*}$

( I-כOS) $\lambda$ 
Dr. F. Paoloni, Univ. of Wollongong, AUSTRALIA

Prof. M.H. Brennan, Univ. of Sydney, AUSTRALIA

Plasma Research Lab., Australian Nat. Univ., AUSTRALIA

Prof. I.R. Jones, Flinders Univ, AUSTRALIA

Prot. F. Cap, Inst for Theoretical Physics, AUSTRIA

Prof. M. Heindler, Institut fur Theoretische Physik, AUSTRIA

Prof. M. Goossens, Astronomisch Instituut, BELGIUM

Ecole Roysde Militaire, Lab. de Phy. Plasmas, BELGIUM

Commission-Europern, DG. XII-Fusion Proo., BELGIUM

Prot. R. Boucique, Rijksuniversiteit Gent, BELGIUM

Dr. P.H. Sakanaka, Instituto Fisica, BRAZIL

Instituto Neciond De Pesquiens Especisis-INPE, BRUZIL

Documents Olíce, Atomic Enorgy of Canada Lid., CANADA

Dr. M.P. Bachynskj, MPB Technologies, Inc., CANADA

Dr. H.M. Skaregard, Univ. of Sackatchowan, CANADA

Prof. J. Teichmann, Univ. of Montrea, CANADA

Prof. S.R. Sreenivasen, Univ. of Calgary, CANADA

Prof. T.W. Johnston, INAS-Energio, CANADA

Dr. A. Bolton, Centro canadien de fusion magnótique, CANADA

Dr. C.R. James., Univ. of Aberta, CANADA

Dr. P. Luktc, Komenakeho Universzita, CZECHOSLOVAKIA

The Librarien, Cuthem Laboratory. ENGLAND

Libray, R61, Ruthortord Appleion Laboratory, ENGLAND

Mrs. S.A. Hutchinson, JET Library, ENGLAND

Dr. S.C. Shema, Univ. of South Pacific. FIJI ISLANDS

P. Makonon, Univ. of Herisintivi, FINLAND

Prof. M.N. Buseac, Eouk istytechnique, FRANCE

C. Mouttot, Lab. do Phyciepses des Milioux lonises, FRANCE

J. Radet, CENCADARACHE - Bat 506, FRANCE

Prof. E. Economou, Univ. of Crete, GREECE

Ms. C. Rinni, Univ. of loannina, GAEECE

Dr. T. Mud, Academy Bibliographic Ser., HONG KONG

Proprint Librery, Mungarian Academy of Sci., HUNGARY

Or. B. DasGupta, Saha Inst of Nuctoser Ptysics, INDIA

Di. P. Kaw, Inst. for Plasma Research, INDIA

Dr. P. Roseneu, lereed Inst. of Technology, ISRAEL

Librarien, Intemations Center for Theo Phycics, ITALY

Miss C. De Palo, Associazione EURATOMENEA, ITALY

Dr. G. Grosso, Istituto di Fisica del Plasma, ITALY

Prof. G. Rostangni, Istituto Gas lonizzati Ded Cnr, ITALY

Dr. H. Yamato, Tochiba Res Devol Center, JAPAN
Prof. I. Kawakami, Hiroshima Univ., JAPAN

Prof. K. Nishikawa, Hiroshima Univ., JAPAN

Director, Japen Atomic Energy Research Inst., JAPAN

Prof. S. Itoh, Kyushu Univ., JAPAN

Research Into. Ctr., National Instit. for Fusion Science, JAPAN

Prof. S. Tanaka, Kyoto Univ., JAPAN

Librany, Kyolo Univ., JAPAN

Prot. N. Inove, Univ. of Tokyo, JAPAN

Secretary, Plasma Section, Electrotectnical Lab., JAPAN

S. Mori, Techniced Advisor, JAERI, JAPAN

Dr. O. Miterai, Kumamoto Inst of Technology, JAPAN

J. Hyoon-Sook, Korea Atomic Enorgy Research Inst., KOAEA

D.I. Chai. The Korea Ady. Inst. of Sci. Toch., KOREA

Prof. B.S. Liby, Univ. of Waikato, NEW ?EALAND

Inst of Physics, Chinese Acad Sci PEOPLE'S REP. OF CHINA

Librey, Inst of Plasma Physics, PEOPLE'S REP. OF CHINA

Tsinghua Univ. Library, PEOPIE'S REPUBLIC OF CHINA

Z. Li, S.W. Inst Physics, PEOPLE'S REPUBUC OF CHINA

Prof. J.A.C. Cebra, Instituto Superior Tecnico, POATUGAL

Dr. O. Potrus, Al I Cuza Univ., Romania

Dr. J. de Viliers, Fucion Studies, AEC, S. AFRICA

Prof. M.A. Hellberg, Univ. of Natal, S. AFRICA

Prof. D.E. Kim, Pohang Inst. of Sci. \& Tech., SO. KOAEA

Prof. C.I.E.M.A.T. Fusion Division Library, SPAIN

Dr. L Sienfio, Univ. of UMEA, SWEDEN

Librey, Royal Inst. of Tectnology, SWEDEN

Prot. H. Wheimeon, Chaimors Univ. of Tech., SWEDEN

Centre Phys. Des Plasmas, Ecole Polytech, SWITZERLAND

Bibliotheek, Inst. Voor Plasma-Fysica, THE NETHERLANDS

Aest. Prof. Dr. S. Ceitir, Midde East Tech. Univ., TURKEY

Dr. V.A. Gukhikh,Sci. Pos. Inst. Eloctrophys.I Apparatus, USSR

Dr. D.D. Ayutoy, Siberien Brench of Acedemy of Sa., USSA

Dr. G.A. Elicoev, I.V. Kurchatov Inst, USSA

Librarian. The Ukr.SSR Academy of Scionces, USSR

Dr. LM. Kovizhmykh, Inst. of General Physics, USSA

Kemforschungeanlago GmbH, Zentrabibliothek, W. GERMANY

Bibliothok, Inst For Plasmaforechung, W. GERMANY

Prof. K. Schindor, Puhr-Universitt Bochum, W. GERMANY

Dr. F. Wagner, (ASDEX), Max-Planck-Institut, W. GERMANY

Librarien, Max-Planck-Instiut, W. GERMANY

Prof. R.K. Janev, Inst. of Ptysics, YUGOSLAVIA 

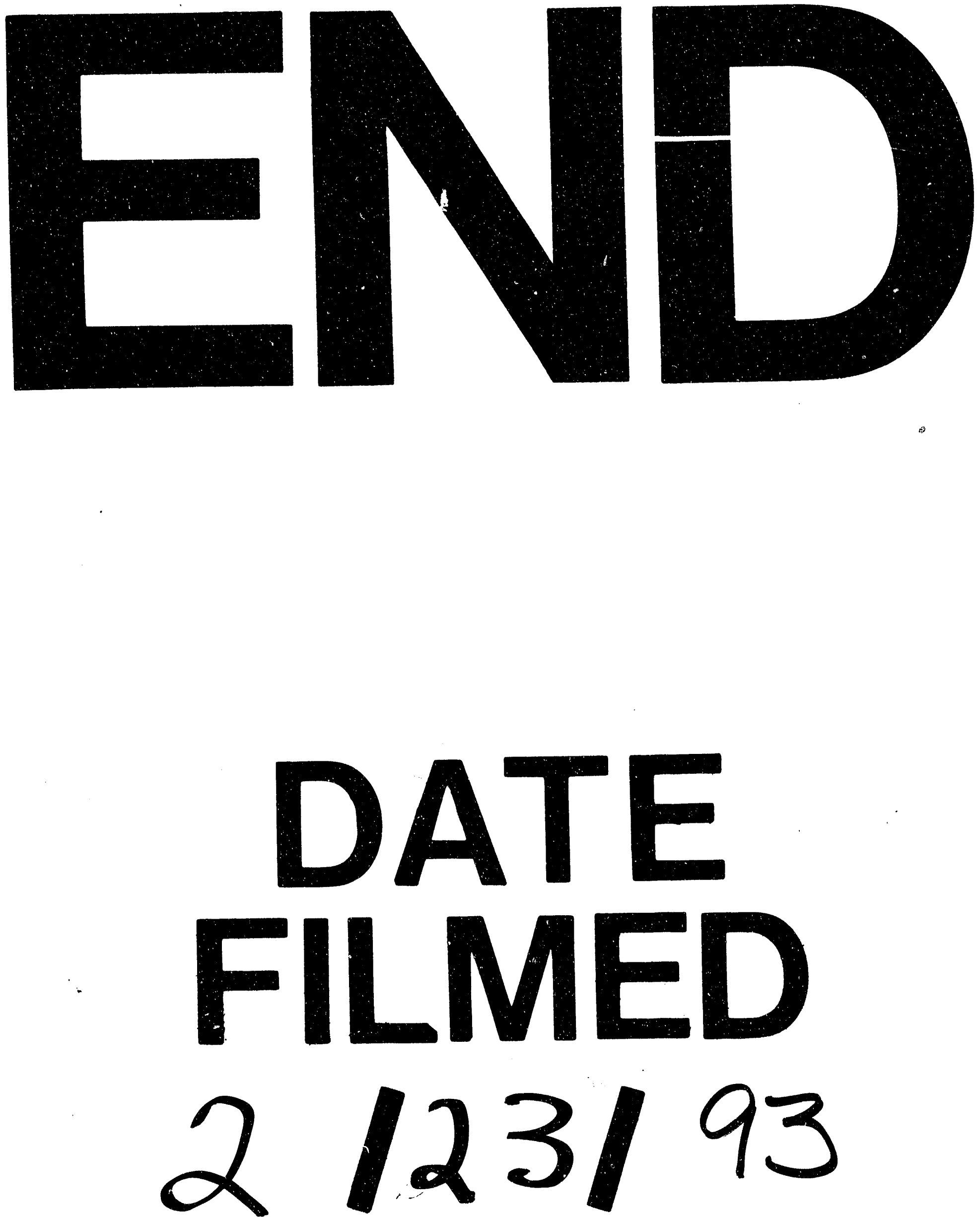
